\title{
KIẾN THỨC VỀ BÊNHH LAO CỦA BÁC SĨ CÔNG TÁC TẠI TRAM Y TẾ XÃ/PHƯỜNG Ở MộT Số TỈNH MIỀN BẮC NĂM 2019-2020
}

\section{TÓM TẮT}

Một yếu tố vô cùng quan trọng quyết định sự thành công của công tác phòng chống lao là các bác sĩ cần có đầy đủ kiến thức về bệnh lao. Nghiên cứu mô tả cắt ngang được tiến hành nhằm mô tả môt số kiến thức cớ bản về bênh lao của bác sĩ công tác tại tram y tế xã/phường ở một số tỉnh miền Bắc, năm 2019-2020. Có 335 bác sĩ công tác tại TYT tham gia nghiên cứu. Thông tin được thu thâp bằng bô câu hỏi tự điền. Kết quả nghiên cứu cho thấy tuổi trung bình của các bác sĩ là $40,3 \pm 9,2$. Kiến thức về bênh lao của bác sĩ công tác tại TYT là tương đối cao. Kiến thức về phân loại bệnh, nguyên nhân gây bệnh, đường lây có tỷ lệ trả lời đúng caoo, lần lượt là: 99,7\%, 97\% và $97,3 \%$. Tuy nhiên, vẫn chỉ có $54,6 \%$ bác sĩ trả lời đúng cân lấy ba mấu đờm để chẩn đoán bệnh. Chưa thây sự khác biệt về mức độ kiến thức bệnh lao theo thâm niên công tác, giới tính. Trung bình số câu trả lời đúng (trong tổng số 9 câu hỏi về nguyên nhân và chẩn đoán bênh lao) ở nhóm bác sĩ nữ và bác sĩ nam là 7,92 và 7,88 ; các bác sĩ ở độ tuổi $35-45$ có số câu trả lời đúng là 7,97 câu. Kết quả cho thấy các bác sĩ công tác tại TYT xã có kiến thức về nguyên nhân và chẩn đoán bệnh lao là tương đối cao, điều này rất quan trong trong công cuốc phòng chống bênh lao

Tư khóa: bệnh lao, kiến thức, bác sĩ, trạm y tế

\section{SUMMARY}

KNOWLEDGE ABOUT TUBERCULOSIS AMONG DOCTORS AT COMMUNE HEALTH STATIONS IN SOME NORTHERN PROVINCES IN 2019-2020

An extremely important factor determining the success of tuberculosis (TB) prevention is that doctors have to adequate knowledge about TB. A crosssectional study was conducted. The study described some basic knowledge about tuberculosis among doctors at commune health stations in some northern provinces, in 2019-2020. There were 335 doctors working at CHS participating in the study. Information was collected using self-administered questionnaire. The results indicated that average age of heath staff was $40.3 \pm 9.2$. Knowledge about tuberculosis of doctors working at CHS was relatively high. Knowledge about disease classification, disease causes, and transmission routes had a high rate of correct answers, respectively: $99.7 \%, 97 \%$ and $97.3 \%$. However, only $54.6 \%$ of doctors who answered correctly needed to take three sputum

*Trường Đại học Y Hà Nội

Chịu trách nhiếm chính: Lưu Đình Lập

Email: luudinhlap@gmail.com

Ngày nhận bài: 6.5.2021

Ngày phản biên khoa hoc: 25.6.2021

Ngày duyệt bài: 5.7.2021

\section{Lưu Đình Lập*, Nguyễn Phương Hoa*}

samples for diagnose TB. There was no difference in the level of TB knowledge by seniority, gender. The average number of correct answers (out of a total of 9 questions about the cause and diagnosis of TB) among groups of female and male doctors were 7.92 and 7.88; doctors aged $35-45$ got 7.97 correct answers. The results showed that doctors at CHSs had a relatively high knowledge of the causes and diagnosis of TB, which is very important in the prevention of TB.

Keyword: tuberculosis, knowledge, doctor, commune health station

\section{I. ĐẶT VẤN ĐỀ}

Lao là một bênh đã được biết đến từ rất lâu nhưng cho đến nay vẫn là một trong những bênh lây nhiễm có số người mắc và tử vong cao trên thế giới. Mặc dù từ khi phát hiện được nguyên nhân cũng như tìm ra thuốc điều trị bênh có hiêu quả nhưng bệnh lao không những không giảm mà còn có xu hướng gia tăng ở nhiều nước. Bệnh lao là một trong mười nguyên nhân tử vong hàng đâu trên toàn câu. Theo số liêu thống kê của Tổ chức $Y$ tế Thế giới (WHO) ước tính năm 2019 có khoảng 1,7 tỉ người nhiễm lao, mỗi năm phát hiện thêm khoảng 10 triệu ca mắc lao mới và ước tính có khoảng 1,2 triểu ca tử vong do lao ở những người âm tính với HIV và thêm 251.000 ca tử vong trong số những người nhiễm HIV [1]. Tại Việt Nam bệnh lao vẫn là một vấn đề sức khỏe trầm trọng, Viêt Nam đứng thứ 16 trong 30 nước có số người bệnh lao cao nhất trên toàn câu, đồng thời đứng thứ 13 trong số 30 nước có gánh nặng bệnh lao kháng đa thuốc cao nhất thế giới (Theo báo cáo WHO 2019)[2]. Từ năm 1999, chiến lược DOTS (điêuu tri bằng hóa trị liệu ngắn ngày có kiểm soát trực tiếp) đã được bao phủ trên $100 \%$ số quận, huyê̂n trong cả nước. Tuy nhiên, cùng với đại dịch HIV/AIDS, tình hình kháng thuốc và sự gia tăng dân số đang tác động và làm gia tăng bệnh lao tại cộng đồng.

Trong công cuộc phòng chống và tiến tới chấm dứt bệnh lao, trạm y tế xã đóng một vai trò hết sức quan trọng: trạm y tế là cơ sở y tế gân dân nhất đồng thời cũng là nơi triển khai công tác phát hiện người nghi lao, tham gia chẩn đoán, điều trị, dự phòng và quản lý bệnh nhân lao tại cộng đồng. Một yếu tố vô cùng quan trọng quyết định sự thành công của công tác phòng chống lao tại tuyến y tế cơ sở (YTCS) nói 
chung và trạm y tế xã/ phường (TYT) nói riêng là nhân viên y tế cần có đầy đủ kiến thức về phòng chống bệnh lao, trong đó các bác sĩ tại TYT đóng vai trò hat nhân. Vì vây, nghiên cứu này được tiến hành với mục tiều: Mô tả kiến thức về bệnh lao của bác sĩ công tác tại trạm y tế xã/phường ở một số tỉnh miền Bắc, năm 2019-2020.

\section{II. ĐỐI TƯỢNG VÀ PHƯƠNG PHÁP NGHIÊN CỨU}

1. Đối tượng nghiên cứu. Bác sĩ công tác tại TYT xã/phường ở một số tỉnh miền Bắc là: Hà Nội, Hà Giang, Ninh Bình, Điện Biên và Yên Bái.

\section{2. Đia điểm và thời gian nghiên cứu}

Nghiên cứu được tiến hành tại một số tỉnh: Thành phố Hà Nội, tỉnh Ninh Bình, tỉnh Điện Biên, tỉnh Hà Giang và tỉnh Yên Bái. Số liệu được thu thập trong khoảng thời gian từ tháng 9/2019 đến tháng 10/2020.

\section{Phương pháp nghiên cứu}

Thiết kế nghiên cứu: Nghiên cứu mô tả cắt ngang.

Cỡ mẫu nghiên cứu: Áp dụng công thức tính cỡ mẫu cho nghiên cứu mô tả để xác định một tỷ lệ.

n: cõ mẫu

$$
\mathbf{n}=Z^{2} 1-\alpha / 2 \frac{p(1-p)}{(p \varepsilon)^{2}}
$$

a : Mức ý nghĩa thống kê (Chọn $\alpha=0,05 \rightarrow$ $\left.Z_{1-\alpha / 2}=1,96\right)$

ع: Khoảng sai lệch tương đối giữa mẫu nghiên cứu và quần thể. Chọn $\boldsymbol{\varepsilon}=0,08$

p: Tỷ lệ dựa vào các nghiên cứu tương tự đã thực hiện trước đó

Về kiến thức: Theo nghiên cứu của Nguyễn Phương Hoa tại Ba Vì năm 2005 thì điểm kiến thức về bệnh lao trung bình của ĐTNC là 15,59/23 (trả lời đúng trung bình $68 \%$ số câu hỏi). Cỡ mẫu tính toán được là 282 người. Cõ mẫu được cộng thêm $15 \%$ phòng trường hợp từ chối trả lời, nên cõ̃ mẫu là 324 bác sĩ. Thực tế nghiên cứu điều tra được 335 bác sĩ.

Phương pháp thu thập số liệu: Các bác sĩ công tác tại TYT tham gia lớp tập huấn CME về YHGĐ và các bác Sĩ TYT trong các cuộc họp/giao ban tại TTYT được phát phiếu điều tra để tự điền và hoàn thành phiếu. Nghiên cứu viên giải thích về mục đích và hướng dấn hoàn thành phiếu (tự làm dựa vào kiến thức của cá nhân mình, không trao đổi với đồng nghiệp, điền đủ các câu, không bỏ sót câu...). Các bác sĩ hoàn thành phiếu dưới sự giám sát nghiên cứu viên. Bộ câu hỏi được xây dựng dựa trên những kiến thức mà Chương trình Chống lao Quốc gia hướng dẫn TYT thực hiện và
Hướng dẫn chẩn đoán và điều trị bệnh lao của Bộ Y tế bao gồm những kiến thức cơ bản như triệu chứng bệnh, đường lây, chẩn đoán, điêu trị và theo dõi điêu tri....

Phương pháp phân tích và xử lý số liệu: Các số liệu được làm sạch, mã hóa và nhập, được phân tích bằng phần mềm SPSS Statistics 20.0; tính tần suất, tỷ lệ phần trăm, các giá trị trung bình, độ lệch chuẩn (SD), và tỷ suất chênh (OR), 95\% CI.

Test Chi- Square $\left(x^{2}\right)$ được sử dụng để so sánh các tỷ lê (Fisher's exact test được sử dung thay thế khi có giá trị kì vọng nhỏ hơn 5). Test T-student và ANOVA được sử dụng để so sánh sự khác biệt giữa các giá trị trung bình.

Đạo đức nghiên cứu: Nghiên cứu này chỉ sử dụng phương pháp thu thập số liệu qua bộ câu hỏi thiết kế săn nên không gây tác hại cho các đối tượng tham gia nghiên cứu. Các đối tượng tham gia nghiên cứu được giải thích về mục đích điều tra, nội dung thông tin cần thu thập, tự nguyện đồng ý tham gia, được giữ bí mật và số liệu được sử dụng cho mục đích nghiên cứu.

\section{KẾT QUẢ NGHIÊN CỨU VÀ BÀN LUÂNN \\ 1. Một số đặc điểm chung của đối tượng} nghiên cứu

Bảng 1. Đặc điểm chung của đôî tượng nghiên cứu ( $n=335)$

\begin{tabular}{|c|c|c|c|}
\hline \multicolumn{2}{|c|}{ Đặc điểm chung } & \multirow{2}{*}{$\begin{array}{c}\begin{array}{c}\text { Số lượng } \\
\text { (n) }\end{array} \\
118\end{array}$} & \multirow{2}{*}{$\begin{array}{l}\text { Tí lệ } \\
(\%) \\
35,2\end{array}$} \\
\hline \multirow{3}{*}{ Nhóm tuổi } & $<35$ tuối & & \\
\hline & 35-45 tuối & 92 & 27,5 \\
\hline & $>45$ tuối & 125 & 37,3 \\
\hline \multirow{3}{*}{$\begin{array}{l}\text { Thâm niên } \\
\text { công tác }\end{array}$} & $<10$ năm & 110 & 32,8 \\
\hline & 10-20 năm & 121 & 27,8 \\
\hline & > 20 năm & 104 & 39,4 \\
\hline \multirow{2}{*}{$\begin{array}{c}\text { Được tập huấn } \\
\text { phòng chống } \\
\text { bệnh lao }\end{array}$} & Có & 154 & 46 \\
\hline & Không & 181 & 54 \\
\hline \multirow{2}{*}{ Dân tộc } & Kinh & 282 & 84,2 \\
\hline & Khác & 53 & 15,8 \\
\hline
\end{tabular}

Tuối trung bình ( $\overline{\times} \pm$ SD) năm: 40,3 $\pm 9,2$

Thâm niên công tác $\times($ SD) năm: $15,3 \pm 9,2$

Nhân xét: Độ tuối trung bình của các bác sî là $40,3 \pm 9,2$, người nhiều tuổi nhất là 60 tuổi, người ít tuổi nhất là 25 tuổi. Các bác sĩ có thâm niên công tác trung bình là $15,3 \pm 9,2$, người có thâm niên công tác lâu nhất là 40 năm, người có thâm niên công tác ít nhất là 1 năm.

Trong số 335 bác sĩ trả lời phỏng vấn có 154 người (46\%) đã tham gia khóa tập huấn phòng chống bệnh lao, 181 người (54\%) chưa tham gia. 


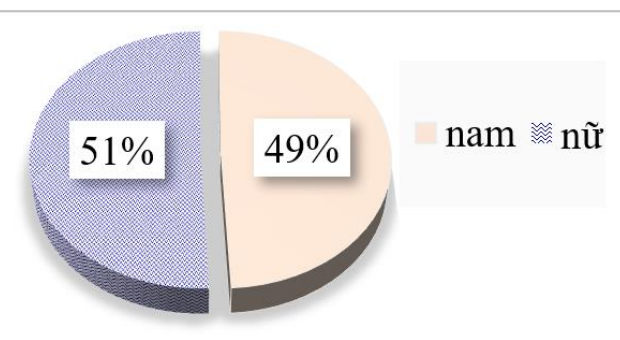

Biểu đồ 1. Phân bố đôi tượng nghiên cứu theo giới tính

Nhận xét: Số lượng bác sĩ nam và nữ tham gia trả lời phỏng vấn là tương đương nhau.

2. Kiến thức về bệnh lao của bác sĩ

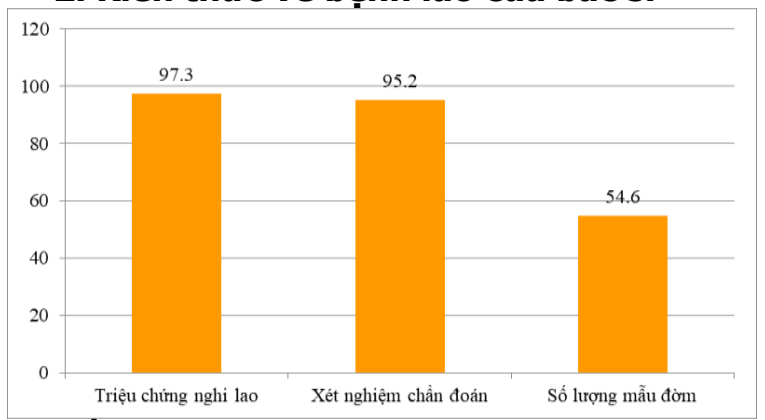

Biểu đồ 3. Kiến thức về triệu chứng nghi lao và chẩn đoán bệnh lao

Về chẩn đoán bệnh lao, hầu hết các bác sĩ đều trả lời đúng câu hỏi về triệu chứng nghi ngờ mắc bệnh lao $(97,3 \%)$ và làm xét nghiệm đờm để chẩn đoán bệnh lao (95,2\%). Tuy nhiên, chỉ có $54,6 \%$ các bác sĩ được hỏi trả lời đúng cần lấy 3 mẫu đờm để chẩn đoán bệnh lao.

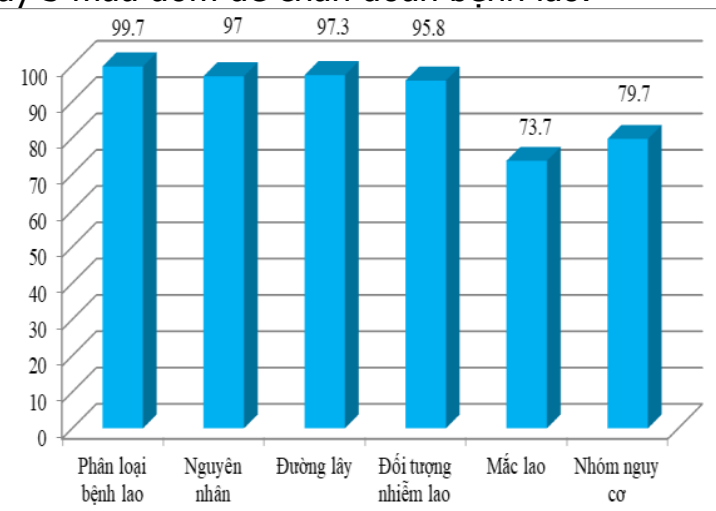

Biểu đồ 2. Kiến thức về nguyên nhân và đôî tượng nguy cơ cao măc bệh lao

Tỉ lệ trả lời đúng về kiến thức chung về bệnh lao tương đối cao, trong đó hầu hết các bác sĩ đều trả lời đúng bênh lao là bệnh truyền nhiễm $(99,7 \%)$ do vi khuẩn lao gây nên $(97 \%)$. Tuy nhiên, chỉ có $73,7 \%$ các bác sĩ trả lời đúng câu hỏi "tất cả những người nhiễm lao đều trở thành bênh nhân lao" và 79,7\% các bác sĩ trả lời đúng đối tượng nguy cơ cao nhiễm lao.

Bảng 2. Một số kiến thức cơ bản về bệnh lao theo giới tính

\begin{tabular}{|c|c|c|c|c|c|}
\hline \multirow{3}{*}{ Nội dung } & \multicolumn{4}{|c|}{ Giới tính } & \multirow{3}{*}{ p } \\
\hline & \multicolumn{2}{|c|}{$\operatorname{Nam}(n=165)$} & \multicolumn{2}{|c|}{ Nũ̃ $(n=170)$} & \\
\hline & $\mathbf{n}$ & $\%$ & $\mathbf{n}$ & $\%$ & \\
\hline Lao là bệnh lây nhiếm & 164 & 99,4 & 170 & 100 & 0,493 \\
\hline Bệnh lao là do vi khuấn lao gây ra & 161 & 97,6 & 164 & 96,5 & 0,861 \\
\hline Bệnh lao lây qua đường hô hấp & 162 & 98,2 & 164 & 96,5 & 0,502 \\
\hline Đối tượng nào bị nhiếm lao & 160 & 97 & 161 & 94,7 & 0,369 \\
\hline Bị nhiềm lao đều trở thành bệnh nhân lao & 117 & 70,9 & 130 & 76,5 & 0,391 \\
\hline Đối tượng nguy cơ cao mắc bệnh & 128 & 77,6 & 139 & 81,8 & 0,498 \\
\hline Triệu chứng nghi ngờ mắc bệnh lao & 160 & 97 & 166 & 97,6 & 0,860 \\
\hline Xét nghiệm giá trị trong chấn đoán & 157 & 95,2 & 162 & 95,3 & 0,429 \\
\hline Số lượng mấu đờm cần thu thập trong chẩn đoán & 92 & 55,8 & 91 & 53,5 & 0,809 \\
\hline $\begin{array}{l}\text { Về kiến thức chung bệnh lao: số câu trả lời } \\
\text { đúng của các bác sĩ nữ cao hơn so với các bác sĩ } \\
\text { nam ở các câu lao là bệnh lây nhiễm ( }(100 \% \text { so } \\
\text { với } 99,4 \%), \text { bị nhiễm lao đều trở thành bệnh } \\
\text { nhân lao ( } 76,5 \% \text { so với } 70,9 \%) \text {, đối tượng nguy } \\
\text { cơ cao mắc bệnh }(81,8 \% \text { so với } 77,6 \%) \text {; các câu } \\
\text { còn lại như nguyên nhân gây bệnh, đường lây, } \\
\text { đối tượng bị nhiếm lao số câu trả lời đúng bác sĩ } \\
\text { nam cao hơn. Tuy nhiên, khác biệt này không có }\end{array}$ & \multicolumn{5}{|c|}{ 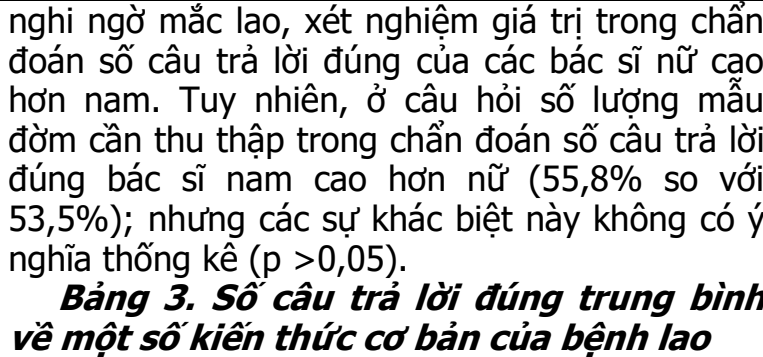 } \\
\hline $\begin{array}{l}\text { ý nghĩa thống kê ( } p>0,05) \text {. } \\
\text { Về chẩn đoán bệnh: ở các câu triệu chứng }\end{array}$ & \multicolumn{2}{|c|}{$\begin{array}{c}\text { Các yếu tố liên } \\
\text { quan }\end{array}$} & $\begin{array}{c}\text { (Trung } \\
\text { bình) }\end{array}$ & $\begin{array}{l}\text { SD (đồ } \\
\text { chuẩ }\end{array}$ & $\mathbf{p}$ \\
\hline
\end{tabular}




\begin{tabular}{|c|c|c|c|c|}
\hline \multirow{2}{*}{ Giới } & Nam & 7,88 & 1,04 & \multirow{2}{*}{0,727} \\
\hline & Nữ & 7,92 & 0,98 & \\
\hline \multirow{3}{*}{$\begin{array}{l}\text { Thâm } \\
\text { niên }\end{array}$} & $<10$ năm & 7,81 & 1,12 & \multirow{3}{*}{0,208} \\
\hline & $\begin{array}{c}10-20 \\
\text { năm }\end{array}$ & 7,86 & 0,98 & \\
\hline & $>20$ năm & 8,05 & 0,92 & \\
\hline \multirow{3}{*}{$\begin{array}{c}\text { Nhóm } \\
\text { tuổi }\end{array}$} & $<35$ tuối & 7,86 & 1,06 & \multirow{3}{*}{0,731} \\
\hline & $35-45$ & 7,97 & 0,94 & \\
\hline & > 45 tuối & 7,90 & 1,02 & \\
\hline \multirow{2}{*}{$\begin{array}{c}\text { Tập } \\
\text { huấn }\end{array}$} & Có & 7,86 & 0,94 & \multirow{2}{*}{0,425} \\
\hline & Không & 7,94 & 1,07 & \\
\hline
\end{tabular}

Nhận xét: Số câu trả lời đúng về một số kiến thức cơ bản của bệnh lao ở nhóm nữ giới cao hơn nam giới (7,92 so với 7,88); thâm niên công tác càng cao thì số câu trá lời đúng càng cao $(8,05$ so với 7,86 và 7,81$)$; các bác sĩ ở đô̂ tuổi 35-45 có số câu trả lời đúng cao nhất là 7,97 câu; các bác sĩ không tham gia tập huấn có số câu trả lời đúng cao hơn các bác sĩ có tham gia tập huấn $(7,94$ so với 7,86$)$. Tuy nhiên, các sự khác biệt này đều không có ý nghĩa thống kê $(\mathrm{p}>0,05)$.

\section{BÀN LUÂN}

Đặc điểm chung của đối tượng nghiên cứu. Độ tuổi trung bình của các bác sĩ công tác tại TYT xã là $40,3 \pm 9,2$, bác sĩ trẻ nhất là 25 tuổi và nhiều tuổi nhất 60 tuổi. Kết quả này cao hơn so với một nghiên cứu tại Maseru năm 2015 cho thấy các NVYT có độ tuổi trung bình là 30,76 $\pm 6,84$ [3]. Một nghiên cứu khác tại Uganda cũng cho thấy độ tuổi trung bình của nhân viên y tế được phỏng vấn là 35,6 tuổi [4].

Trong số 335 bác sĩ tham gia nghiên cứu thì bác sĩ nam chiếm $49,3 \%$ và bác sĩ nữ chiếm $50,7 \%$. Kết quả nghiên cứu này cũng tương đương với một nghiên cứu tiến hành tại Ba Vì thì số NVYT nam chiếm $43,5 \%$ và số NVYT nữ chiếm 56,5\% [5]. Theo nghiên cứu tại Maseru cho thây có $40 \%$ NVYT là nam và $60 \%$ NVYT tham gia trả lời là nữ [3].

Trong số các bác sĩ tham gia trả lời phỏng vấn có $46 \%$ các bác sĩ đã được tham gia các khóa đào tạo phòng chống bệnh lao, con số này cao hơn so với nghiên cứu tại Ba Vì năm 2005 có kết quả số NVYT tham gia các khóa đào tạo phòng chống bệnh lao chỉ là 39,5\% [5].

Kiến thức về bệnh lao. Kết quả nghiên cứu cho thây kiến thức chung về bệnh lao của các bác sĩ công tác tại TYT xã là khá cao. Theo nghiên cứu của chúng tôi có tới 99,7\% các bác sĩ trả lời đúng bệnh lao là một bệnh truyền nhiễm, $97 \%$ các bác sĩ có kiến thức đúng về nguyên nhân gây bệnh lao, con số này cao hơn so với nghiên cứu được tiến hành tại Ba Vì với $90 \%$ đối tượng được phỏng vấn trả lời đúng [5]. Một nghiên cứu khác tại Nga năm 2008 cũng cho thấy có $90 \%$ số người tham gia trả lời đúng về nguyên nhân gây bệnh lao [6].

Nghiên cứu cũng chỉ ra rằng có $97,3 \%$ bác sĩ trả lời đúng về đường lây bệnh lao, con số này cao hơn so với nghiên cứu được tiến hành tại Nepal năm 2017 với 81,6\%.

Trong số các câu hỏi kiến thức chung về bệnh lao, câu hỏi có tỉ lệ trả lời đúng thấp nhất là bị nhiếm lao đều trở thành bệnh nhân lao với chỉ $73,7 \%$ bác sĩ trả lời đúng. Tuy nhiên, kết quả này vẫn cao hơn khá nhiều so với nghiên cứu tại Nepal với 54,7\% đối tượng tham gia phân biệt được nhiễm lao và mắc bệnh lao [8].

Hầu hết các bác sĩ tham gia nghiên cứu đều có kiến thức về phát hiện triệu chứng nghi ngờ mắc bệnh lao $(97,6 \%)$ và xét nghiệm đờm là xét nghiệm quan trọng nhất để chẩn đoán bệnh lao $(95,3 \%)$. Điều này rất có ý nghĩa vì muổn phát hiện sớm bệnh nhân lao tại cộng đồng các bác sĩ cần có kiến thức và phản xạ phát hiện người nghi mắc lao. Triệu chứng nghi lao chính là ho kéo dài, đây là triệu chứng sớm và gặp phổ biến ở hầu hết các bệnh nhân lao. Tuy nhiên, cùng với các triệu chứng sốt, mệt mỏi và chán ăn, cộng với ho kéo dài làm cho mọi người dễ nhầm lấn với cảm cúm hay viêm họng thông thường. Việc các bác sĩ nắm chắc được triệu chứng này có ý nghĩa rất lớn trong việc chẩn đoán sớm bênh lao giúp cho viêc điêu trị có hiêuu quả hơn, phòng tránh sự lây lan ra cộng đồng. Kết quá này cao hơn so với các nghiên cứu tiến hành trước đây: nghiên cứu tại tại Pakistan năm 2018 cho thây khoảng $92 \%$ nhần viên được phỏng vấn biết rằng ho dai dẳng là triệu chứng của bệnh lao, $82 \%$ biết rằng bệnh lao được chẩn đoán bằng cách kiểm tra đờm [7]. Một nghiên cứu khác được tiến hành tại Nepal năm 2017 cho kết quả chỉ có $67,4 \%$ NVYT chọn ho dai dẳng trên 2 tuần là triệu chứng chính của bệnh lao [8].

Tuy nhiên, kiến thức về số mẫu đờm cần thu thâp để chẩn đoán bệnh lao của các bác sĩ khá thấp chỉ chiếm khoảng $53,5 \%$. Con số này thấp hơn so với nghiên cứu được tiến hành tại Ba Vì năm 2005 với $64,8 \%$ các NVYT trả lời đúng cần lấy 3 mẫu đờm để chẩn đoán bệnh lao [5].

Nghiên cứu của chúng tôi cho thấy kiến thức về bệnh lao và chẩn đoán bệnh lao của các bác sĩ công tác tại TYT xã là khá cao. Các bác sĩ đã có những kiến thức cơ bản như: nguyên nhân gây bệnh, đường lây, đối tượng có thể nhiễm lao cũng như biết được các triệu chứng lâm sàng và 
xét nghiệm cận lâm sàng cần có để có thể chẩn đoán chính xác bệnh lao. Bên cạnh đó vẫn còn một số kiến thức có tỉ lệ trả lời đúng thấp như: phân biệt người nhiễm lao và người mắc bệnh lao, về số mầu đờm cần lấy để chẩn đoán bệnh. Vì vậy cần cung cấp thêm thông tin của những khía cạnh này cho các bác sĩ công tác tại trạm y tế xã.

\section{KẾT LUẬN}

Độ tuổi trung bình của các bác sĩ tại TYT là $40,3 \pm 9,2$, thâm niên công tác trung bình là $15,3 \pm 9,2$, số lượng bác sĩ nữ và bác sĩ nam là tương đương nhau (49,3\% so với 50,7\%).

Kiến thức cơ bản về bệnh lao của bác sĩ tại TYT là tương đối cao. Trong đó các kiến thức về phân loại, nguyên nhân gây bệnh, đường lây có hầu hết các bác sĩ đã trả lời đúng với tỉ lệ lần lượt là: $99,7 \%, 97 \%$ và $97,3 \%$.

Các bác sĩ công tác tại TYT đã nắm được các kiến thức về triêu chứng và xét nghiệm cận lâm sàng cần làm để chẩn đoán bệnh lao. Tuy nhiên, chỉ có $54,6 \%$ bác sĩ trả lời đúng cần lấy ba mẫu đờm để chẩn đoán bệnh lao.

Chưa thấy sự khác biệt về các kiến thức cơ bản của bệnh lao theo nhóm tuổi, giới tính và thâm niên công tác.

\section{TÀI LIÊU THAM KHẢO}

1. World Health Organaization (2019), Global tuberculosis report 2019, 52-59.

2. Bộ Y tế (2020). Hưởng ứng Ngày Thế giới phòng chống lao 24/3/2020, tổng kết hoạt động phòng chống lao năm 2019 và triển khai kế hoạch năm 2020.

3. Malangu N. và Adebanjo O.D. (2015). Knowledge and practices about multidrug-resistant tuberculosis amongst healthcare workers in Maseru. Afr J Prim Health Care Fam Med, 7(1).

4. Buregyeya E., Kasasa S., và Mitchell E.M.H. (2016). Tuberculosis infection control knowledge and attitudes among health workers in Uganda: a cross-sectional study. BMC Infect Dis, 16(1), 416.

5. Nguyến Phương Hoa (2005). Diagnosis and treatment of pulmonary tuberculosis at basic health care facilities in rural Vietnam: a survey of knowledge and reported practices among health staff.

6. Woith W.M, Volchenkov G and Larson J.L (2010). Russian healthcare workers' knowledge of tuberculosis and infection control. Int J Tuberc Lung Dis Off J Int Union Tuberc Lung Dis, 14(11), 1489-1492.

7. Mustafa T, Shahzad Y and Kiani A (2018). A survey of knowledge, attitude, and practices of private retail pharmacies staff in tuberculosis care: study from Dera Ismail Khan City, Pakistan. J Pharm Policy Pract, 11, 7. 42-47.

8. Shrestha A, Bhattarai D, Thapa B et al. (2017). Health care workers' knowledge, attitudes and practices on tuberculosis infection control, Nepal. BMC Infect Dis, 17(1), 724-731.

\title{
ĐĂC ĐIỂM HÌNH ẢNH CộNG HƯỞNG TỪ CỦA U MÀNG NÃO Ở NGƯỜI LỚN
}

\author{
Nguyễn Hữu Hoạt ${ }^{1}$, Nguyễn Xuân Khái ${ }^{2}$, \\ Ngô Tuấn Minh², Nguyễn Việt Dũng ${ }^{2}$, Trần Công $\mathrm{Hoan}^{3}$
}

\section{TÓM TẮT}

Mục đích: Đánh giá đặc điểm hình ảnh công hưởng từ (CHT) của u màng não (UMN) ở người lớn. Đối tượng và phương pháp nghiên cứu: Nghiên cứu hồi cứu kết hợp tiến cứu, mô tả cắt ngang 76 bênh nhân với 81 khối u được chẩn đoán, phâu thuât và có kết quả mô bệnh học là UMN tại khoa Phấu thuật thần kinh, Bệnh viện Việt Đức và Bệnh viên Quân y 103 trong thời gian từ tháng 10/2020 đến tháng 03/2021. Kết quả: Phần lớn là u đơn độc $(96,1 \%)$, bờ đều $(67,9 \%)$, kích thước trung bình $40,19 \pm 16,45 \mathrm{~mm}$. Khối u đồng tín hiệu trên T1W và

${ }^{1}$ Bệnh viện đa khoa Hoàn Mỹ

Bệnh viện Quân y 103

${ }^{3}$ Bềnh viện $E$

Chịu trách nhiệm chính: Nguyễn Việt Dũng

Email: dung.nguyenviet.cdha@gmail.com

Ngày nhận bài: 4.5.2021

Ngày phản biên khoa học: 24.6.2021

Ngày duyệt bài: 5.7.2021 tăng nhe tín hiệu trên T2W, tỷ lệ lần lượt là $66,7 \%$ và $65,4 \%$. Sau tiểm, đa số u ngấm thuốc đồng nhất (79\%), dấu hiệu đuôi màng cứng quan sát thây ở $60,5 \%$ tổng số u. Các thần phần vôi hóa, nang trong $\mathrm{u}$, chảy máu trong u chiếm tỷ lệ lần lượt là $12,3 \%$, $2,5 \%$ và $16,0 \%$. Phù não quanh u găp ở $59,3 \%$. Tỷ lế chèn ép động mạch, chèn ép xoang tĩnh mạch và chèn ép thần kinh lần lướt là $22,2 \%, 38,3 \%$ và $28,4 \%$. Có 9,9\% số khối u có biến đổi xương cạnh u. Kết luân: CHT là phương pháp chẩn đoán hình ảnh có giá trị cao trong chẩn đoán UMN cũng như đánh giá mức độ xâm lấn các tổ chức xung quanh $u$, giúp ích cho chẩn đoán và tiên lượng.

Tư khóa: Cộng hưởng từ, u màng não.

\section{SUMMARY}

MAGNETIC RESONANCE IMAGING FEATURES OF MENINGIOMAS IN ADULTS

Objectives: Evaluate magnetic resonance imaging (MRI) characteristics of meningioma in adults. Subjects and methods: Retrospective combined with prospective research, cross-sectional description 